This report was prepared as an account of work sponsored by the United States Government. Neitlier the United States nor the United States Atomic Energy Commission, nor any of their employees, nor any of their contractors, subcontractors, or their employees, makes any warranty, express or implied, or assumes any legal liability or responsibility for the accuracy, completeness or usefulness of any information, apparatus, product or process disclosed, or represents that its use would not infringe privately owned rights.

\author{
Session 1.2 \\ A/CONF.49/\%.033 \\ Conf- $710901-32$
}

\title{
GLOBAL EFFECTS OF INCREASED USE OF ENERGY
}

\author{
Alvin M. Weinberg and R. Philip Hammond \\ Oak Ridge National Laboratory \\ Oak Ridge, Tennessee
}

\section{INTRODUCTION}

We in the peaceful nuclear energy community have been comfortable in the belief that what we have wrought over the past 30 years has been an unmitigated blessing for mankind. It comes as a disconcerting shock therefore to find that, just when nuclear energy has achieved such great success, our effort is being challenged on the most fundamental grounds. Where we claim nuclear energy is clean, safe, and necessary, critical voices, particularly in the United States, claim it is unclean, unsafe, unnecessary.

We have always conceded that, in opting for nuclear energy, mankind is assuming a certain risk. Nuclear energy is potentially more dangerous than other forms of energy. It is only by scrupulous attention to detail, and exertion of great care, that we can expect to maintain the safety of nuclear power plants. So far, we have been highly successful.

Yet there is a much more difficult and profound issue. We are still at the very beginning of the nuclear age. As we think about the possibilities and the dangers of nuclear power, we tend inevitably to think of nuclear power as an isolated, smallish thing. But in the very long run, nuclear energy will almost surely be the dominant energy source. At that time, will we have to confront entirely new questions of environmental impact, questions that conceivably could compromise the whole path we are now taking?

In this paper, we shall try to visualize the possible ultimate impacts of nuclear energy. We shall consider several interrelated questions. First, what is the motivation for the large-scale development of nuclear energy? Second, can we estimate, even very roughly, what the world's eventual nuclear energy budget might be? And third, can we visualize limits to the ultimate use of nuclear energy - such as limits to reserves of raw materials, global thermal effects, questions of disposal of radioactive and other wastes produced in the course of generating the ultimate budget of nuclear energy?

This paper is, by the nature of its subject matter, speculative. Yet the questions it raises in our opinion go to the very heart of the motivation for nuclear energy and to the ultimate risks of the new energy source. If the motivation is sufficiently strong, we must be prepared to deal with the risks. But we cannot be content with examining the risks when nuclear energy is relatively unimportant; we must try to assess the risks ultimately, when both the need for 


\section{DISCLAIMER}

This report was prepared as an account of work sponsored by an agency of the United States Government. Neither the United States Government nor any agency Thereof, nor any of their employees, makes any warranty, express or implied, or assumes any legal liability or responsibility for the accuracy, completeness, or usefulness of any information, apparatus, product, or process disclosed, or represents that its use would not infringe privately owned rights. Reference herein to any specific commercial product, process, or service by trade name, trademark, manufacturer, or otherwise does not necessarily constitute or imply its endorsement, recommendation, or favoring by the United States Government or any agency thereof. The views and opinions of authors expressed herein do not necessarily state or reflect those of the United States Government or any agency thereof. 


\section{DISCLAIMER}

Portions of this document may be illegible in electronic image products. Images are produced from the best available original document. 
nuclear energy and the risks of nuclear energy are much greater than they are now. These questions, though admittedly speculative, seem to us to be of great concern to all of us attending the Fourth Geneva Conference on Peaceful Uses of Atomic Energy.

\section{THE MOMENTUM OF POPULATION GROWTH}

In the world we see ahead, the race to control overpopulation subordinates all other problems. In this world it is our thesis that nuclear energy is the key resource, vital to our survival and yet controllable and manageable in its effects and by-products.

One of the most alarming aspects of the population problem is that of momentum. As yet no universally acceptable method of fertility control is in sight, but even if we had such a method now, the population would continue to increase for 50 to 80 years. Demographers [1] have identified several mechanisms which operate to produce this momentum effect. These include: the age distribution of the population, which insures a large increase even if each couple should begin at once to limit themselves to two children; the diffusion time required to introduce and educate all the people of the world in the methods of fertility control; and the time needed to develop incentive, which in many countries means that parents must acquire either sufficient material wealth for their old age or sufficient confidence that the survival of only two children will meet their needs. With respect to this last point, it may be that assuring every person adequate old-age insurance whether or not he has children would be a most important step in halting the growth of population. All these delaying factors operate most strongly in the very parts of the world where population is increasing at the highest rates.

The consequences predicted by demographers are shown in Fig. 1, with the different stable populations associated with various times of discovery of a practical birth control means. They state, and we have no choice but to accept, that an ultimate population of 10,000 million persons is very likely, that something like 15,000 million is quite likely, and that 20,000 million is not impossible.

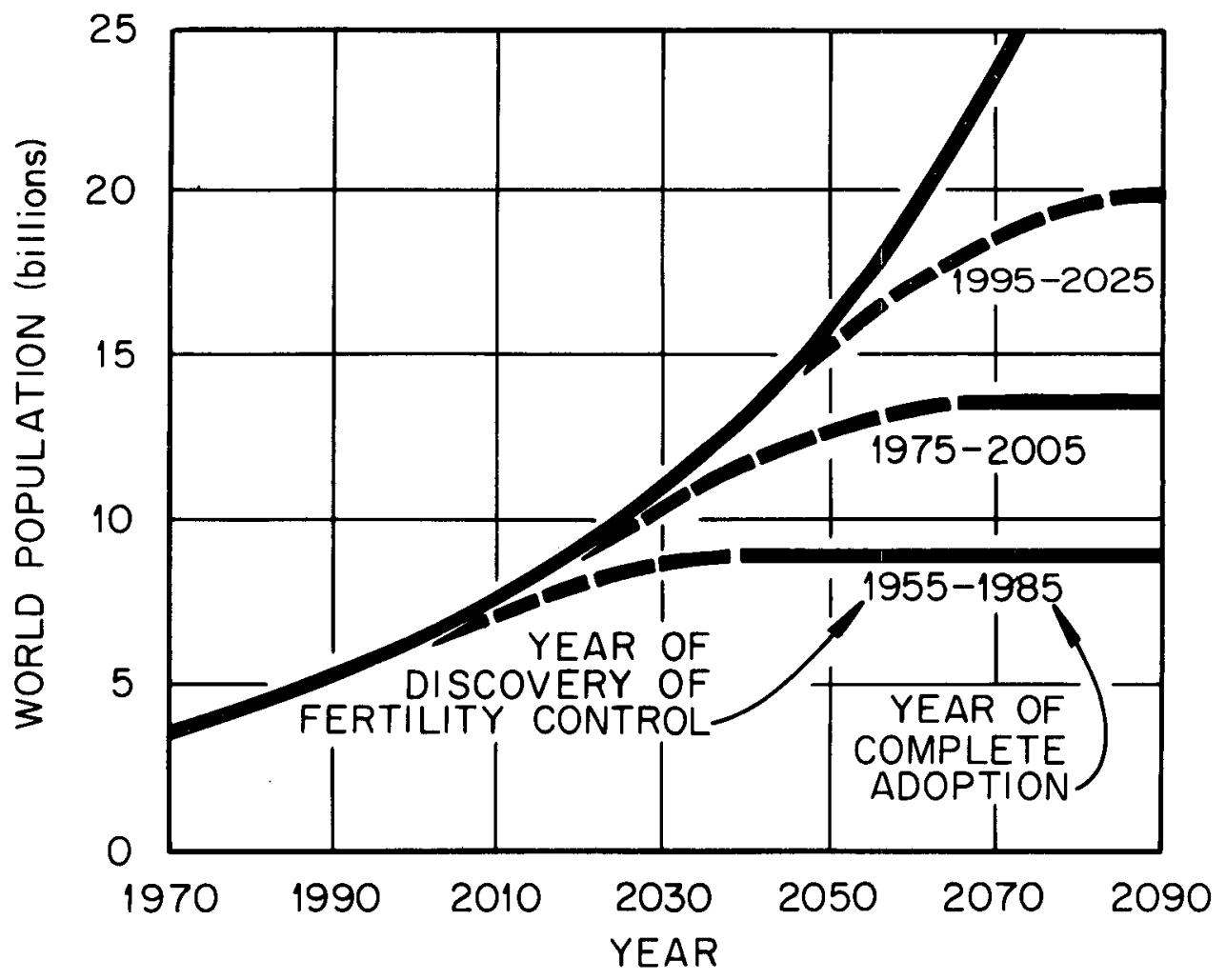

Fig. 1. Effect of Momentum in Population Growth. 
It is our purpose, then, to assess the future consequences of our nuclear technology on a world which is highly likely to materialize. Because we are prepared to discuss the consequences of providing for 15,000 million people does not mean we recommend such a level as desirable we accept it only because we see no acceptable, humane way to prevent it. We utilize 15,000 million as an example - we could have used 12,000 or 20,000 with equal support from authority, and with little effect on our conclusions.

\section{ENERGY, THE KEY RESOURCE}

Let us turn our attention to a time, perhaps 100 years hence, in which parents have been averaging only two children for 50 years or so, and population has finally stabilized at 15,000 million persons.

The importance of energy in such a world becomes immediately apparent: we cannot hope to feed such a population without significant nonfarm energy inputs, even using all the arable land on earth. With such inputs, however, in the form of fertilizer, water control, and machinery, this might be accomplished on even less land than is now used for crops. Most of this increased food can in principle be produced on existing cropland, though the possibility exists of increasing our land supply by using the desert. In previous work sponsored by the U.S. Atomic Energy Commission, some of which is to be presented at this conference by Commissioner Ramey, it has been shown that energy can convert seawater, air, and desert land into hydrogen and fertilizers, fresh water, foods, and industrial goods by means of an agro-industrial complex.

But energy is essential in another basic way, for not only is the food requirement inconsistent with subsistence agriculture, but the assumption of zero growth probably implies inherently a degree of wealth and hence of energy use. Even a fully adequate old-age insurance system requires a minimum level of wealth in the society. We assume this level to be the present U.S. level, though our argument is not changed very much even if we assume a level one-half of this.

The requirements for material resources of 15,000 million people at a high standard of living will be unprecedented in terms of our present experience, and this leads to concern as to possible exhaustion of essential supplies. This subject has been reexamined in detail during the past year by H. E. Goeller of Oak Ridge National Laboratory in a cooperative project with Resources for the Future, Inc. Goeller shows [2] that with the possible exception of phosphorus the essential resource requirements of man can be met from plentiful sources for a long time to come, provided that energy is available to do the necessary extractive work. Some substitutions, adjustments, and compromises will be inevitable, and much expensive recycling of scarce substances must be done; but the key requirements appear to be available.

\section{COMPONENTS OF AN ENERGY BUDGET}

At present, the U.S. consumption of energy in all forms has a fuel equivalent of about 300 million Btu per person per year, which is a steady rate of 10 kilowatts thermal [kW(th)] per person. The various uses and activities for this energy have been published [3]. If we assume that the entire world is gradually brought up to this same standard of living [present average is only $1.5 \mathrm{~kW}(\mathrm{th})$ per capita] and that appropriate substitutions of energy are made for those raw materials which are not in virtually limitless supply, we can calculate the total energy budget of civilization at any population level. The basis for these energy inputs is developed elsewhere [4] and summarized in Table I. The final budget of $20 \mathrm{~kW}(\mathrm{th})$ per person (600 million Btu per year) is purposely generous in order to provide a margin of safety in our estimates of consequences. 
Table I. Energy Budget per Capita for a Steady-State Civilization

(kilowatts fuel equivalent)

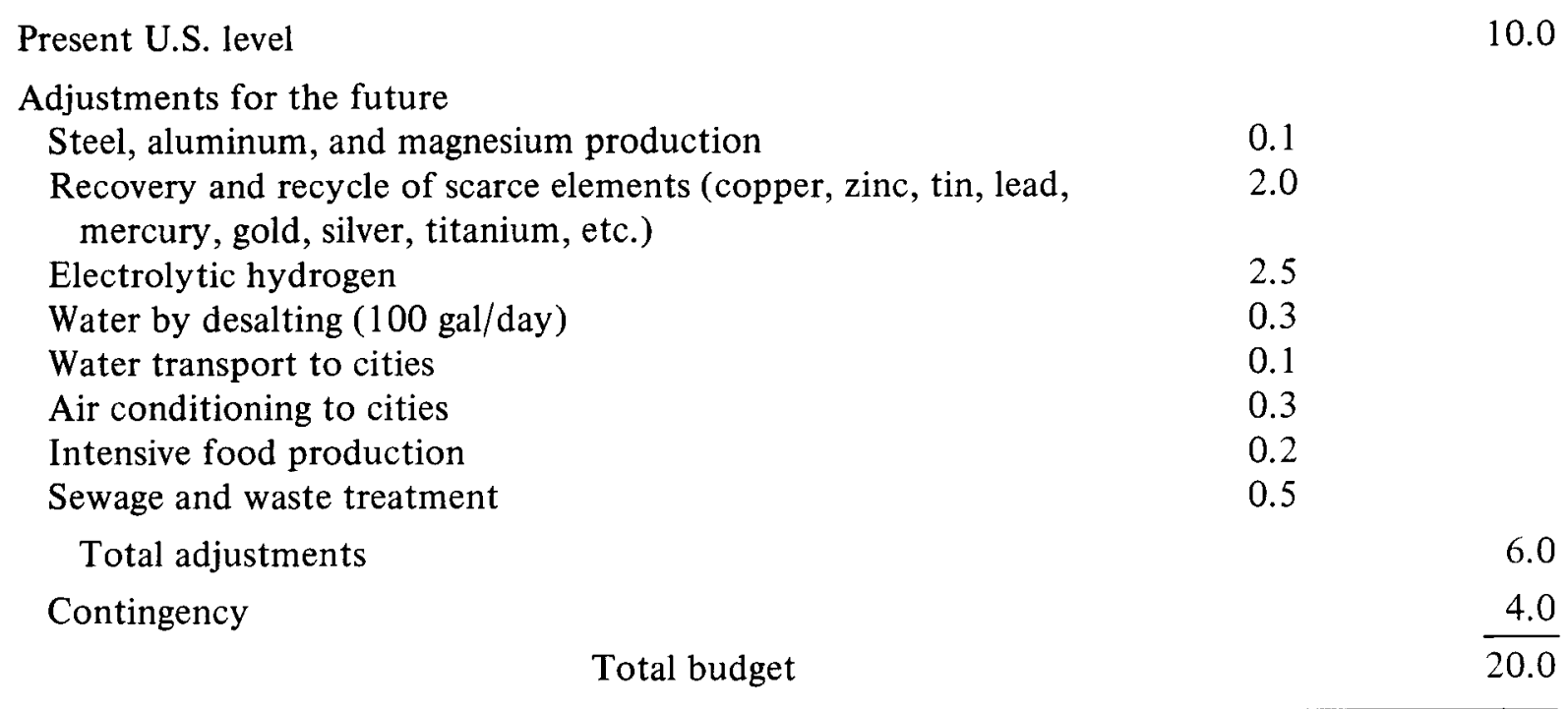

\section{SITES FOR ENERGY PRODUCTION: ENERGY PARKS}

In hypothesizing a world in which energy is the basic raw material, we need to give some thought to how and where it is produced. The past few years have brought about a crisis in site selection for power stations, both nuclear and fossil. The choicest sites near plentiful cooling water are increasingly forbidden to power stations, both for financial and ecological reasons. As the trend to nuclear power accelerates, other factors appear which tend to favor very large reactors with nearby captive fuel processing plants: these might be clustered in "nuclear parks."

One of the most important factors favoring such parks is the difficulty of shipment of spent fuel elements. We have estimated that in the U.S. alone, by the year 2000, if there are 600,000 MW of fast breeder reactors, 60 to 100 batches of spent fuel will be in transit every day. For economy, one would like to ship these fuel elements with not more than, say, 30 days cooling time. But this might require dissipation of $300 \mathrm{~kW}$ of heat from each shipment. Even if we back off from such short cooling times, shipment of fuel looks difficult, and we believe the "nuclear parks" would be a possible alternative. We would hope that developments in long-distance electrical transmission would minimize the penalty paid for clustering the power plants.

Each park might have, say, eight reactors producing a total of 40 million kilowatts electrical [kW(e)] [100 million $\mathrm{kW}(\mathrm{th})$ ] and would be heavily interconnected with other parks so that shutdown of one reactor or failure of one transmission line would have negligible effect. If all man's energy needs were produced as nuclear electricity, a total of 3000 such parks would eventually be required to produce our assumed total. Some of these parks will be on the seashore, or preferably floating offshore on huge barges. Not only would it be very difficult to find sites on the land for this many parks, but our analysis of the cost trends shows that ocean siting may become a reasonable alternative for many regions.

It is clear that major changes will be needed in the methods by which we undertake to construct power stations. To attain the assumed level of 24,000 reactors of 5,000 MW(e) each means that the world will have to add more than four reactors a week on the average for the next 100 years. In addition, if the reactors last 30 years, we shall have to build about two reactors per day simply to replace those that have worn out! To meet this kind of need, present-day methods will have to be refined into assembly lines which resemble those which now turn out automobiles; in the process, savings in cost and time should be achievable. 


\section{LIMITS TO THE USE OF ENERGY}

We now explore some of the possible physical and environmental consequences of a world of 15,000 million people living at a U.S. standard and consuming a total of $9 \times 10^{18}$ Btu per year $(9 \mathrm{Q})$, or $300 \times 10^{9} \mathrm{~kW}(\mathrm{th})$. We expect that about 12,000 million persons will live in about a million square miles ( 300 million hectares) of cities covering about $2 \%$ of the earth's surface and supplied with food from efficient farms covering about $10 \%$ or less of the earth's surface.

We shall explore four kinds of limits which nature might conceivably set to the energy consumption which we have hypothesized: supply of fuel, dissipation of heat, storage and release of radioactive wastes, and storage and release of other wastes.

\section{Limits to the supply of fuel}

The supply of nuclear fuel has been much studied, and so we shall deal with it only briefly. Obviously, a steady energy budget of $300 \times 10^{9} \mathrm{~kW}(\mathrm{th})$ or $9 \mathrm{Q}$ per year would deplete our fossil reserves of around $400 \mathrm{Q}$ in a couple of generations. Moreover, it matters little whether our energy budget were, say, threefold smaller: mankind would still have but a hundred years worth of fossil fuel.

If we discount solar energy as being too diffuse and too expensive to utilize, we shall therefore be obliged to turn to nuclear fuel: uranium, thorium, deuterium, lithium.

As is very well known by now, these materials, in the oceans of the sea and in the common rocks, provide enough energy even at the prodigious rate we contemplate, to last a very long time. To tap this resource we must learn to burn deuterium in D-D reactions; or, failing this, to develop ways of burning ${ }^{6} \mathrm{Li},{ }^{238} \mathrm{U}$, or ${ }^{232} \mathrm{Th}$.

The outlook for fusion is covered in other papers at this conference. We wish to point out, however, that there is a striking parallel between fission breeders and fusion based on D-T reactions. In both cases, a regenerating catalyst ( $\mathrm{T}$ in the case of fusion, ${ }^{23}{ }^{9} \mathrm{Pu}$ or ${ }^{23} \mathrm{U}$ in the case of fission) is involved in the conversion of ${ }^{6} \mathrm{Li}$ (and D) or ${ }^{238} \mathrm{U}$ and ${ }^{232} \mathrm{Th}$ into energy. We therefore propose the name catalytic nuclear burners for both fission breeders and fusion reactors based on D-T.

The crustal abundance of ${ }^{6} \mathrm{Li}$ is $2 \mathrm{ppm}$, of $U+\mathrm{Th}$ about $15 \mathrm{ppm}$. Since lithium yields about four times the energy of the same weight of uranium or thorium, the total energy content of each type of fuel in the earth's crust is similar. Both are immense, literally millions of times the energy content of all fossil fuels. Thus if we develop catalytic nuclear burners, either of the fusion or fission type, we have all but inexhaustible sources of fuel to keep them going.

\section{Limits to waste heat release}

\section{Global effects}

We have shown that the overall temperature regime of the earth is unlikely to be noticeably affected by man-made energy. Man presently releases about $0.005 \times 10^{12} \mathrm{~kW}($ th), or one part in about 23,500 of the net solar input of $117.5 \times 10^{12} \mathrm{~kW}(\mathrm{th})$. Our assumed ultimate load is 60 times the present one, or $0.25 \%$ of the net solar input. Estimates show that an overall warming of about $0.1 \mathrm{deg} C$ plus a slight increase in cloudiness (earth's reflectivity changed from 0.340 to 0.34073 , for example) would be a likely effect.

The overall average effects seem reassuring, but we must also consider effects on global weather patterns, which are driven by only a small fraction of the total solar energy, and which might be totally upset by the energy man releases. Although much more thorough study of such effects is needed, we can offer two kinds of specific evidence to illuminate this difficult problem.

Dr. Warren M. Washington of the National Center for Atmospheric Research has shown with computer modeling techniques that energy inputs much larger than we have assumed would not be expected to "upset" the weather, but would slightly reorient isotherm locations within normal ranges [5]. 
Dr. Jerome Namias, chief of the Extended Forecast Division of the National Weather Service, has been studying long-range weather effects caused by the presence of a ten-year-long anomalous warming in the North Pacific Ocean [6]. This warming, representing more than ten times the energy input we have assumed from man for the whole world, produced observable statistical effects on the winter climate of the eastern United States, but there were no upsets and the changes were within the range of normal and acceptable variations.

\section{Local effects: the climate of cities}

The urban "heat island" effect is now well documented. Heat rising from a city creates a turbulent bubble of warm, dry air which deflects the normal air flow upward and over the city. In a recent summary of work on this phenomenon, Peterson [7] notes that a city's structures tend to reduce wind velocities, that the inversion surface further weakens them by deflecting regional wind upward, and that heat released by combustion processes and from solar energy stored in buildings and streets tends to form a convection cell which isolates the urban air mass from the surroundings.

The size and energy release of our cities are now low enough that reasonable efforts at pollution control can keep the air tolerable most of the time. However, as urbanized regions grow closer together and cover hundreds of miles, heat plumes escaping from each dense area may combine to form a larger regional heat island which could produce a stronger convection cell, further reduce ambient wind speed, and feed local heat islands with already polluted air. Our assumed future cities will have to pay close attention to heat releases. An all-electric city would release much less heat, since electric processes are usually more efficient. The quantities of heat rejected in nuclear power generation, however, have to be handled separately. To prevent an aggravation of the regional heat island effect, this heat must not be released to the atmosphere near the city. For a time our needs can be met with cooling ponds, lakes, and rivers; but these ultimately return the energy to the atmosphere over relatively small areas. Gradually we will find that only the ocean can furnish enough capacity to absorb heat and release it over a very large area.

\section{Heat disposal in the ocean}

The ocean has attractive properties as a site for power stations: it is large, it is cold, it is always there, and it is close to most of the large cities of the world. There is rapidly growing interest in the use of the sea for siting, and plans for constructing artificial islands and large floating structures now seem feasible. Improved transmission line systems, such as the supergrid, will be the principal step needed to permit the sea to be used for the majority of our energy sources.

In visualizing future demands upon the sea as a heat receptor, such as for the energy parks described above, we must determine whether there are effects on the sea itself, or on the climate, which would set limits to this kind of use. We would propose that ocean-cooled power stations be provided with sufficiently long intakes so that they can draw from the bottom waters - the cold portion below the region mixed by the waves - and be designed to heat this water only to the temperature of the surface waters. The discharged water would thus create no large thermal gradients, and it would be a source of increased nutrients to the surface water. Isaacs and Schmitt [8] claim that with such artificial upwelling there would be a direct correlation in increased seafood productivity with the energy input. (The cold bottom waters, being denser, will not stay on the surface unless they are warmed.)

The conclusions one can draw as to whether man's energy releases will produce tolerable thermal effects on the earth and its climate must be tentative, since much more study and measurement are needed. The indications seem promising, however, that global upsets in weather and temperature are very unlikely if we are able to distribute the energy released over wide areas of the land or into the sea. In cities, the present patterns of energy release already show local effects which would be dangerously aggravated under the projected increases. We believe that substantial research efforts should be directed to assessing and hopefully mitigating these effects. 


\section{Limits from radioactive waste}

If we do not reduce fusion to reliable practice and therefore must depend on fission breeders, about 500,000 megacuries of long-lived activity producing $3.2 \times 10^{6}$ kilowatts of heat would be generated each year at our assumed energy budget of $300 \times 10^{9} \mathrm{~kW}(\mathrm{th})$ [3] Formidable though this quantity may seem, and important though a satisfactory disposal must be, the difficulties do not appear to set an insuperable limit to the use of nuclear power. The release of radioactive gases from normal operation of reactors seems to be reducible to any desired level - even the natural background level - by application of our rapidly developing containment technology.

In the fuel processing plants, however, one must be prepared to cope with the full problem. The general strategy for the next few decades is to immobilize the nonvolatile elements in ceramic matrices and to store them permanently in underground salt strata; krypton and tritium will be held in live storage until they decay. The techniques for disposal of solidified high level wastes have been developed at Oak Ridge over the past ten years and have been demonstrated in a preliminary way in the field. The U.S. Atomic Energy Commission is presently planning a full-scale field demonstration of storage in salt. The advantage of salt is that it is never in contact with ground water, and it is a good conductor of heat.

Though there are other formations which might serve, there is still a long future ahead even if nothing better than salt is found. We estimate, using currently conceived practices, that our future world would require about 30 square miles of salt strata for waste disposal per year. There are 500,000 square miles of salt in the United States alone and tens of millions throughout the world. Not all of this is suitable for waste disposal, but one cannot escape the impression that the foreseeable future is not endangered by the radioactive waste storage problem.

\section{Limits from other wastes}

As shown in Table II, in 1968 the world dug up sand, gravel, ores, and fuels which had a total volume of 2.32 cubic miles; the great majority of these materials were fuels. The effect of

Table II. Volumes of Minerals Used

\begin{tabular}{lccc}
\hline & \multicolumn{2}{c}{ Million Short Tons } & $\begin{array}{c}\text { Volume } \\
\text { (cubic miles) }\end{array}$ \\
\cline { 2 - 4 } & U.S. & World & 0.37 \\
\hline Sand and gravel & 918 & $3,700^{a}$ & 0.54 \\
Coal and lignite & 556 & 3,086 & 0.20 \\
Limestone & 603 & $2,400^{a}$ & 0.53 \\
Petroleum & 495 & 2,090 & 0.57 ) \\
Natural gas & 493 & 790 & 0.04 \\
Iron ore & 95 & 738 & 0.03 \\
Copper ore & 150 & 491 & 0.02 \\
Phosphate rock $\quad 148$ & $211^{b}$ & 0.01 \\
$\quad$ Marketable) & $(41)$ & $(93)$ & 0.005 \\
Salt & 41 & 124 & 0.004 \\
Gypsum & 9 & 52 & 0.003 \\
Bauxite & 2 & 47 & 1.75 \\
Sulfur and pyrites $\quad 11$ & 44 & 2.32 \\
$\quad$ Total excluding natural gas and liquids & & & \\
$\quad$ Total including natural gas and liquids & & 13,800 & \\
\hline
\end{tabular}

${ }^{a}$ Based on world production $=4 \times$ U.S.

${ }^{b}$ World mined/marketable ore assumed same as U.S. 
these removals on the earth's beauty and usefulness is one which we must take into full account in considering the consequences of a large population. As fuels are consumed and as sand, gravel, and limestone are used in the construction of roads and buildings, we are left with gashes in the earth, missing hills, and subsidence from underground mines and wells. In the case of metal ores, we have in addition the tailings left by beneficiation and extraction of the desired metal; in the case of strip mining of coal, we have the piles of overburden. For each case we must ask if a limit is imposed on man's activities or comfort.

The extraction of petroleum and gas should not cause us much concern, since they will have been exhausted at the time we are considering and will cause no further effect. Coal is a different story. Where strip mining is practiced, there is often five times as much overburden to remove as there is coal to recover. Since we have assumed we will require a total of nearly $250 \mathrm{Q}$ of energy in the next 100 years, and six cubic miles of coal is required to give one $Q$, one can see that several thousands of cubic miles of overburden may be involved if coal remains our principal fuel.

If uranium is substituted for coal as the source of energy, the quantities of debris to be handled are reduced by two or three orders of magnitude. The ores now being used are thousands of times smaller in volume than the equivalent energy in coal; even the shales and richer granites, which will last for hundreds of thousands of years, need only a hundredth of the volume of coal to give the same energy content. The advent of nuclear power will reduce man's per capita earth moving by nearly $50 \%$ overall. The remainder is mostly sand, gravel, and limestone, which are available so profusely that we have wide choice in locating our borrow pits for minimum damage to the environment.

\section{CONCLUSION}

Though our paper is speculative, we believe we have made a plausible case for two major theses:

1. That mankind must have an alternative, essentially inexhaustible energy source. From what we now know, this source must be nuclear.

2. That there probably are no insuperable global effects even if nuclear energy from fission breeders reaches 60 times the total energy man now produces.

Thus we are persuaded that the underlying motivation for development of nuclear energy is valid, despite the noisy criticism which is being leveled at the enterprise.

Nevertheless we would do well to contemplate the full implications of a complete commitment to nuclear energy. Mankind, as the price of relief from Malthusian catastrophe, will have to confront all of the side effects of catalytic nuclear burners directly and realistically. Such matters as ultimate disposal of radioactive wastes, shipment of spent fuel elements, even the remote possibility of accident, which seem to be relatively minor questions today, become totally dominant when nuclear power generates the prodigious amounts of energy contemplated here.

Are we doing mankind a service in pointing out that with abundant energy, we can take care of many more people than now inhabit this earth; or would we do better to ignore these possibilities and thus force population control by tightening the Malthusian vise, by not holding out hope for this energy panacea? The answer seems clear to us: since there is no assurance that population control will work no matter what measures, what social pressures, are brought to bear, we have no choice, as compassionate technologists and human beings, but to examine ways of dealing with the population catastrophe that seems to be inevitable. Perhaps by providing a material basis for lives of dignity for the coming billions, we may be helping more to stave off the ultimate catastrophe of population explosion than by tightening Malthusian vises. It is this belief that should motivate the nuclear community in its effort to develop safe, clean, economic catalytic nuclear burners. 
9

REFERENCES

[1] KEYFITZ, NATHAN, On the momentum of population growth, Demography 8 (1971) $71-81$.

[2] GOELLER, H. E., A Mineral Resources Primer, to be published.

[3] WEINBERG, A. M., HAMMOND, R. P., Limits to the use of energy, Amer. Sci. 58 (1970) 412-418.

[4] HAMMOND, R. P., unpublished manuscript.

[5] WASHINGTON, W. M., On the possible uses of global atmospheric models for the study of air pollution, presented at the Workshop on Research Problems in Air and Water Pollution, University of Colorado, Boulder, August 3-15, 1970.

[6] NAMIAS, J., Climatic anomaly over the United States during the 1960's, Science 170 (1970) 741-742.

[7] PETERSON, J: T., The Climate of Cities: A Survey of Recent Literature, U.S. Dept. of Health, Education and Welfare, October 1969.

[8] ISAACS, J. D., SCHMITT, W. R., Stimulation of marine productivity with waste heat and mechanical power, J. Conseil Perm. Inter. Exploration Ger 331 (1969) 20-29.

$$
\begin{aligned}
& 3-5057 \\
& 3-15 / 9
\end{aligned}
$$

$$
3-6981
$$

* av is. Howell said This was newer published only
existed in draft form. 